Capítulo 14

\title{
CICATRICES EN LA MEMORIA: POSCONFLICTO, MASS MEDIA Y VÍCTIMAS. UN ACERCAMIENTO CUALITATIVO A LA TIERRA DEL OLVIDO
}

Edimer Leonardo Latorre-Iglesias ${ }^{1}$

\section{Resumen}

El capítulo de libro sintetizo las diversas investigaciones jurídicas y sociojurídicas desarrolladas desde el grupo de investigación Joaquín Aarón Manjarrés que pertenece a la Escuela de Derecho de la Universidad Sergio Arboleda-Santa Marta. Señala los resultados de investigación, las dinámicas conflictivas derivadas de la relación global-local, así como la importancia de propiciar escenarios de visibilización de las tragedias no publicables de las víctimas del conflicto silenciadas en las agendas mediáticas, así mismo, insiste en la necesidad de instaurar una memoria jurídica que logre propiciar escenarios transicionales para materializar efectivamente la no repetición.

1 Doctor en Sociología Jurídica e Instituciones Políticas de la Facultad de Derecho de la Universidad Externado y Posdoctor en Educación, Ciencias Sociales e Interculturalidad de la Universidad Santo Tomás. Reconocido como investigador Senior en la convocatoria de Colciencias número 781 del año 2017, actualmente se desempeña como director del grupo de investigación categorizado en Al Joaquín Aarón Manjarrés, adscrito a la Escuela de Derecho de la Universidad Sergio Arboleda seccional Santa Marta. Email: edimer.latorre@ usa.edu.co 
Palabras clave: Memoria jurídica, posconflicto, víctimas, medios de comunicación y sociedad transicional.

\section{Abstract}

The book chapter synthesizes the various legal and socio-legal investigations developed by the research group Joaquin Aaron Manjarres of the Law School of the Sergio Arboleda University of Santa Marta. They indicate the results of research, the importance of propitiating scenarios of visibility of the unpublished tragedies of the victims army conlflicts silenced in the mediatic agendas, likewise, insists on the need to establish a legal memory that manages to propitiate transcendental scenarios of non-repetition.

Keywords: Legal memory, post-conflict, victims, media and transitional society.

\section{Introducción}

La Nación colombiana después de más de cinco décadas de conflicto y de un largo proceso de diálogo con la guerrilla de las Farc, inicia un proceso transicional, que algunos denominan postacuerdo, otros postconflicto (De la Calle, 2019). Este interregno vital, implica asumir el tremendo desafío de la reconstrucción del tejido social, pero también conlleva a la necesaria solución de los problemas históricos no resueltos, en la convulsa y violenta conformación del Estado-Nación. Uno de estos conflictos, que retorna constantemente con la fuerza de las postergaciones estructurales, es la brecha existente entre el país urbano y el país rural o entre el país legal y el país real

La República no constituyó, pues, en un principio, una primera palabra pronunciada sobre la nada del caos originario, sino un nuevo y magnífico escenario, lleno de posibilidades, en el cual habría de continuar la vieja controversia entre los poderes de la riqueza y el ideal de la justicia que mantiene abiertas, para todos, las puertas de la nacionalidad y sus beneficios. Con la tremenda eficacia perturbadora de los problemas no resueltos, este conflicto repercute todavía, con todas sus consecuencias, en nuestra época. (Lievano Aguirre, 2015, p. 22). 
Pese a que más del 30\% de la población colombiana vive en el campo y que el área rural del territorio es mayor que el área urbana, tradicionalmente la inequidad, así como los diversos conflictos asociados a la tenencia de la tierra se han mantenido como una constante socio-política en la conformación de la Nación colombiana. Paradójicamente, y en contravía de lo que dicta el sentido común, la riqueza agrícola del país ha condenado a los campesinos a asumir un estatus de ciudadanía postergada en derechos y en inclusión social. Ser campesino en Colombia implica ser más pobre, carecer de los recursos y servicios idóneos y sus ingresos son menores en comparación con el de los habitantes de las ciudades.

Según el Fondo Internacional para el Desarrollo Agrícola (FIDA, 2015), de los 11 millones de campesinos colombianos, 7 millones están por debajo de la línea de pobreza y otros 2 millones son indigentes. Sus niveles educativos estadísticamente son inferiores en comparación con los centros urbanos, el $56.8 \%$ de los jefes de hogares residentes en el área rural solo han alcanzado la primaria completa, el 20.1\% ningún nivel educativo y solo el $9.5 \%$ posee la básica secundaria. Aunque la agricultura es la principal fuente de trabajo en el ámbito rural, es el sector con menor remuneración salarial, con tan solo $\$ 815.989$ pesos mensuales como pago en promedio (DANE, 2016).

Posiblemente esta escisión entre los centros urbanos y la periferia, o entre la ciudad y el campo, posibilite explicar las dinámicas del conflicto, que se dio con mayor fuerza en el ámbito rural, esta violencia también se padeció en las zonas agrarias con potencial extractivista (oro, carbón, petróleo, esmeraldas) y en las zonas estratégicas como corrededores para cultivar, procesar y transportar la valiosa hoja de coca. Paulatinamente en la conformación sociohistórica de la Nación Colombiana las fracturas entre el centro y la periferia nos permite acercarnos a una teoría de la dualidad (Acemoglu y Robinson, 2012), esta dualidad propone entender los fenómenos alterlegales como subproducto de la existencia de instituciones que lo posibilitan: la dialéctica negativa entre las instituciones extractivas y las instituciones inclusivas. Pero es necesario recalcar, que el buen funcionamiento de lo institucional y la creación de círculos virtuosos, dependerá en gran medida de qué tan cercanas están las instituciones del Estado a los centros urbanos. 
Estas exclusiones binarias, es decir las brechas entre el mundo urbano y el mundo rural en Colombia, se preservan en la coyuntura actual, que en medio de las luchas políticas polarizantes, motivadas para acabar los recientes acuerdos de paz o para poder materializarlos de una forma efectiva, no permite asumir de manera decisiva (en el diseño de las políticas públicas, ni en las orientaciones de las acciones estratégicas del Estado colombiano), los lineamientos para solucionar de fondo los problemas eternizados en las postergaciones históricas. Sumado a ello, existe en este momento una lucha por la instrumentalización del relato histórico donde es factible evidenciar, como se plantea más adelante en este texto, una colonización de la opinión pública y una manipulación soterrada y en ocasiones evidente de la memoria histórica del conflicto. Los hechos indican que se propende por instaurar una narrativa pseudo histórica que niega el conflicto e invisibiliza las tragedias padecidas por las víctimas, abriendo la posibilidad del olvido y por ende, de la consecuente repetición.

En este sentido, la estructura argumental de los resultados de las investigaciones que se sintetizan en este capitulo de libro, giran, en un primer momento, sobre un acercamiento a las lógicas del análisis globallocal (glocal) de las diversas manifestaciones de lo que se entiende como efectos problémicos locales, derivados de la acción o inacción de un Estado frágil y en ocasiones colapsado. En un segundo momento, se analiza el rol de los mass media en la invisibilización simbólica y fáctica de tales problemáticas, especialmente se enfatiza en el ocultamiento, postergado aún en la actualidad, de la memoria del conflicto y del duelo de relatos que implica su proceso de resignificación a nivel regional y obviamente nacional. En este orden de ideas, el presente escrito asume las construcciones indagativas sobre la memoria como un palimpsesto, es decir, un documento que se reescribe y que debe contener todos los trazos plasmados en el mismo, en este enfoque los procesos de análisis sobre la memoria se reconstruyen desde la perspectiva del retrato a varias manos, de tratar de lograr abarcar el coro polifónico de los co-implicados, y de señalar la importancia del giro cualitativo en la mira, dado que lo esencial en los trabajos de la memoria, es el retorno al sujeto y la resignificación de su experiencia.

Finalizamos el trabajo, con un llamado a la imperiosa necesidad de redignificar las investigaciones sobre memoria, este imperativo, desde luego transforma la manera en que se abordan los problemas, entendiendo la 
necesidad de dar mayor realce a lo que tienen para decir las víctimas, pues como Rulfo escribió: (...) las palabras que había oído hasta entonces (...) no tenían ningún sonido, no sonaban; se sentían, pero sin sonido, como las que se oyen durante los sueños." (1983, p.47). Es de anotar que el simple hecho de visibilizar las cicatrices de una memoria silenciada, puede propiciar colectivamente, la tan anhelada certeza de no repetición, especialmente cuando los escenarios transicionales lo exigen, ya que la resiliencia emana de la forma como portamos nuestras cicatrices y de la manera como colectivamente las asumimos, solo así encontraremos la fuerza necesaria para instaurar el camino hacia la concreción de una memoria jurídica, desde el relato de los silenciados y postergados históricamente, para que por fin, sus palabras resuenen más fuertes, sean escuchadas y salgan del umbral de las pesadillas.

\section{La lógica del abordaje socio-jurídico: globalización, Estado dual y élites familiares}

Basta dar una ojeada a la voluminosa bibliografía sobre el conflicto en Colombia para encontrar diversos enfoques, muchos de ellos aceptados durante décadas, hasta tal punto que los violentólogos siguen partiendo del entendimiento de la multicausalidad como explicación al conflicto y sus efectos colaterales (Oquist, 1978), o la casi aceptada teoría de la ausencia de un proyecto colectivo (Bushnell, 2007), incluso, últimamente han tomado fuerza la perspectiva de análisis sociobiológicos que asumen con mucha plausibilidad nuestra genealogía fundacional, como la causante de todos nuestras tragedias (Serrano, 2016).

El pasado solo habrá sido superado el día en que las causas de lo ocurrido hayan sido eliminadas. Y si su hechizo todavía no se ha roto hasta hoy, es porque las causas siguen vivas. (Adorno, 1998, p. 29)

Lo cierto es que cuando se analizan las investigaciones sobre el conflicto, su perdurabilidad en el tiempo y su capacidad para cooptar y minar el poder de las instituciones, por lo general se soslaya la fuerza global y su incidencias devastadoras en lo local. Como Bauman (2009) ya lo señaló en su momento:

Para resumir: las ciudades se han convertido en el vertedero de problemas engendrados y gestados globalmente. Sus habitantes 
y sus representantes electos deben enfrentarse a una tarea imposible, se mire por donde se mire: encontrar soluciones locales a dificultades y problemas engendrados globalmente. (p. 119-120).

En este sentido, hay que entender las fluctuaciones del Estado Colombiano, en el marco de una institucionalidad precaria y un Estado frágil (Foreing Policy, 2018), en diversas coyunturas muy especificas, transitando el camino de un Estado colapsado. De ahí que el primer análisis de este fenómeno gire en torno al entendimiento de las fuerzas globales que lo modelan, y sin lugar a dudas nos encontramos frente a una potente tendencia macro social derivada de la cara oscura de los fenómenos globales que se denomina grobalización. Este fenómeno, explicado por Ritzer (2007), ubica la globalización como una narrativa seductora que exporta la idea de un acelerado crecimiento económico a aquellos que logren insertarse en las ventajas que ofrece el mercado global, este metarrelato optimista lleno de la euforia del libre comercio y el desarrollo imparable, no deja entrever el lado oculto y pocas veces publicitado de las desventajas del mundo global. Esta versión sombría de la globalización es la que George Ritzer (2007) entiende como Grobalización.

El concepto de lo Global-Grobal podría explicar las fuertes e imparables directrices macro-globales económicas que licuefaccionan los mercados locales, sacando el máximo de ganancias y destruyendo los ecosistemas ambientales básicos como el agua y la tierra. Uno de los axiomas fundamentales de la grobalizacion es acondicionar los marcos normativos de los Estados para que posibiliten su libre accionar y que no coloquen talanqueras al desarollo del capitalismo corporativista y a las técnicas del capitalismo cultural que promueven el consumo desenfrenado (Zizek, 2018). De ahí que sea imprescindible para la grobalización el desmonte de los vestigios del Estado de bienestar, lo que hace que hoy vivamos en un Estado de malestar generalizado (Pardo, 2016), este desmonte gradual es una de las exigencias de las instituciones globales (FMI, BM, BID) en sus recetas, denominadas paquetes de ajuste y que por lo general conllevan de forma cada vez más directa la minimización radical del Estado de bienestar, la desaparición del intervencionismo de Estado y la edificación del Estado regulador de riesgos (Reveiz, 2007). 
En este orden de ideas es que sería posible entender las fluctuaciones y las diferentes crisis del Estado Colombiano, que paradójicamente debe coexistir como una antinomia expresada en la constitución política de 1991, por un lado la defensa del modelo económico clásico del libre mercado (exigida por las fuerzas grobales) y por el otro, la prevalencia de un Estado social de derecho en contravía de las recetas globales. Esta dicotómica conflictividad, termina siendo el nuevo escenario de un combate jurídico por preservar los derechos conquistados en las históricas luchas sociales (Mejía Quintana, 2007 ). Como lo hemos señalado en múltiples apartes (Latorre-Iglesias, 2009, 2012, 2015, 2017) la evidencia de esta pugna entre lo jurídico y lo económico, es la infinidad de protestas sociales que tratan jurídicamente de mantener las conquistas de sus libertades, que le dan vida y aliento al Estado social de derecho y que actualmente corren el riesgo de devenir en ficciones jurídicas altamente simbólicas e imposibles de materializar. Estas luchas en su mayoría, se definen en el escenario de combate del litigio jurídico, que se encuentra en la coyuntura actual, cercado y minado por el capitalismo Grobalizador.

Sumado a lo anterior, los diferentes análisis de las realidades conflictivas y sui generis de Colombia, así como el entendimiento de los efectos devastadores de un conflicto ininterrumpido, no tienen en cuenta la dimensión regional y mucho menos la dimensión municipal. Se habla de guerra, de víctimas, de violencia, desde una visión centralizada y focalizada en las grandes capitales del territorio colombiano, consideramos que la evidencia empírica analizada en las diversas investigaciones desarrolladas por el Grupo de Investigación Joaquín Aarón Manjarrés (Latorre-Iglesias, 2017), plantea la imperiosa necesidad de revisar otra dimensión analítica del conflicto que le imprima mayor exactitud a los estudios y especialmente que permitan entender el panorama local y sus especificidades.

En este sentido podemos afirmar que no existió un conflicto nacional, existió un conflicto que asumió modalidades y variaciones en perspectiva local, que al ser explorada su naturaleza y sus consecuencias, nos aclara que la guerra se vivenció en diferentes intensidades y que estas asimetrías de causa-efecto siguen manteniéndose, dado que no todos los Municipios del país tenían la estructura institucional que les posibilitara atender de manera efectiva, las causas no esperadas de una violencia a gran escala. 
En este orden de ideas es pertinente acercarnos al segundo concepto clave en el desarrollo de estos abordajes: el de la sociedad dual. Tal y como lo expresa Robinson (2014, p. 17-18) "la lectura de la sociedad dual" implica entender que:

Hay un centro del país donde el Estado esta más prente, las leyes y normas mejor ejecutadas y en el que hay menos pobreza; y hay una gran periferia en la que ocurre todo lo contrario. Tal periferia incluye la Costa Caribe, los Llanos Orientales, el litoral Pacífico y las selvas y montañas del sur. La solidez institucional de Colombia se da en el centro. Si hay que hacer algo en Bogotá por medio de la Corte Constitucional o el Banco de la República, entonces puede funcionar. Si es necesario hacerlo en la periferia, como la reforma agraria, no funcionará. Parte de la clave para entender como lo funcional y lo disfuncional coexisten está en entender que los dos están espacialmente diferenciados. Que lo disfuncional esté en la periferia significa que el dolor y el caos que genera se concentran a gran distancia de las élites nacionales.

La coexistencia de dos colombias, una en el centro y otra en la periferia explica fácticamente la permanente prevalencia de las zonas grises, o espacios anómicos (Reyes Morris, 2016), estos espacios anómicos, establecen relaciones heterarquicas para preservarse, eso hace que coexista el código y el contracódigo (Waldman, 2007), que sean constantes las interacciones de intercambio entre lo legal y lo alter legal, o la subsistencia de un mundo normativo que debe luchar denodadamente contra un mundo que no puede regular, cuyas dinámicas interactivas se tornan ilegales y en multiples ocasiones el recurso a la violencia permite su subsistencia. El análisis de la sociedad dual, nos permite acercarnos al tercer concepto clave en este análisis: la teoría de las élites familiares. Entendiendo élites en la perspectiva de Robert Michells, quien señala la fuerte tendencia oligárquica que existe al interior de los procesos sociopoliticos: "La organización es la que da origen al dominio de los elegidos sobre los electores, de los madatarios sobre los mandantes, de los delegados sobre los delegadores, quien dice organización dice oligarquía" (Mitchells, 2008, p. 191).

En este orden de ideas, la mirada a los fenómenos oligárquicos que se dan al interior de toda forma organizacional nos conduce a detenernos 
en el rol determinante de las élites: minorías cerradas que controlan el poder y que basadas en redes de compadrazgo asumen el liderazgo para detentar, otorgar, preservar e incrementar ese poder. En este aspecto es clave el argumento de André Burguiére (1976) quien precisa el rol de las élites familiares en la creación de procesos de estabilidad social en Estados donde el derecho presenta opacidad y debilidad para materializarse, puesto que, a mayor debilidad del Estado y menos posibilidades de acceder a las prerrogativas del mismo, las élites familiares fungen como entes catalizadores del acceso al Estado. Es decir, la relación de poder es inversamente proporcional: a mayor debilidad del Estado, mayor fuerza de la élite familiar. En últimas, de forma anónima, las élites familiares podrían terminar sustituyendo al Estado.

Una definición de la élite familiar enfocada en Latinoamérica y que es bastante útil para el abordaje de la realidad Colombiana, es la planteada por Martin de la Fuente (2018, p. 15), quien después de revisar a 213 miembros de las élites familiares del más alto abolengo en Colombia, y delimitar sus redes de clientela, construye el concepto de la siguiente manera:

La definición de élite como grupo minoritario que controla el poder sobre la mayoría y que además sufre adaptaciones a lo largo del tiempo encajaría mejor en nuestro estudio que los términos que se utilizaron para definir a las familias de abolengo de la etapa colonial y la postindependencia.

El escenario de estas élites familiares colombianas que se adueñan del Estado y que lo cooptan para su beneficio privado, es detallado en su momento de manera retórica en la obra "Los elegidos" (Michelsen, 1953), en la que se puede apreciar en toda su magnitud como la "aristrocracia del más rancio abolengo" lograba de manera descarada transacciones contractuales corruptas, especulaba con información privilegiada y sus prácticas de lobbysmo le permitían adueñarse de los puestos claves en la administración pública, todo esto, obviamente amenizado con whisky, diálogos en inglés y comida gourmet servida en el Atlantic club. La pregunta que se podría formular: ¿qué tanto de lo que se logró bosquejar, paradójicamente por un escritor de la élite, se preserva en la era actual?

El reconocido economista Silva Colmenares (1977) empieza a dar respuesta a este interrogante, cuando señala que las élites familiares son 
propias del capitalismo tardomoderno agenciado en Colombia, cuya base fundamental es la concentración de tierras, el mantenimiento de oligopolios y la propensión a los círculos viciosos: puestos por financiación de campañas, leyes amañadas, políticas públicas que solo benefician a minorias, acompañados de fuertes procesos de desgravación tributaria. En otra arista interpretativa, el sociólogo Francisco Leal Buitrago (2007) señala, que si bien es cierto la existencia, control y mantenimiento de altos privilegios por parte de las élites familiares que han dominado el contexto social y político a nivel nacional, el país en la era contemporánea, enfrenta una lucha entre élites familiares nacionales y élites familiares regionales. Los segundos quieren romper con las cerrazones que imprimía el sistema de la tardomodernidad colombiana, o a mi parecer, de la modernidad colombianizada.

Estos nuevos actores, luchan por ganar un espacio político, social y económico, su ingreso es precisamente logrando sacar a las grandes élites familiares de los fortines políticos cooptados al Estado, enfrentándose por la cooptación de instituciones y sus atractivas burocracias en la arena política. En la lectura de Leal Buitrago, la política regional y las familias que la representan, luchan denodadamente para posicionarse en los espacios políticos Nacionales. El economista ya mencionado Reveiz (2016) señala siete mecanismos de cooptación del Estado y de dominio de lo público, que en la mirada del autor se constituyen en prácticas de trasgresión moral que se convierten en sistemáticas y normalizadas (que el que llegue robe, pero que haga algo): el control del sistema político, la manipulación de la justicia, la economía del narcotráfico, los procesos amañados de contratación pública, los procesos de manejo de la contratación trasnacional, el control de las empresas de la salud y el manejo económico de la información privilegiada. En este sentido, los privilegiados en Colombia enraizados con una visión feudalizante del Estado, a la que denominó González González (2014) como visión "Estado-Hacienda", controlan las localidades más alejadas, es decir, es en las periferias, en la tierra del olvido, donde su liderazgo se preserva en camarillas de poder que secuestran el Estado y minan las instituciones para favorecer sus intereses.

El abordaje al tema de la élite familiar parafraseando a De la Fuente (2018) nos permite concluir que el paisaje de la oligarquía colombiana se preserva, adaptándose a las nuevas exigencias de los contextos globales y 
locales: las fuertes tendencias sociales de los cambios en la estructura social que han golpeado a estas grandes familias, el crecimiento del comercio exterior, el conflicto agrario no resuelto, la evolución y dinámica cambiante del modelo educativo y el desarrollo de los partidos. Estos factores han obligado a las élites a tejer nuevas estrategias e interrelaciones entre si, y con los nuevos actores, en torno al poder, que les brinden la adaptación y la polivalencia necesarias para sostenerse.

Finalizamos este ítem, retomando una de las conclusiones del historiador Caballero (2018), quien destaca un sello especial de los grupos oligárquicos que detentan el poder. La representación de la historia y las narraciones a través de su mirada privilegiada, es decir, la condición particular de crear relatos históricos donde los "otros", los diferentes, en especial los aplazados históricos, no tienen cabida. Veamos el problema de la memoria y el duelo de relatos en una sociedad altamente polarizada y excluyente que tiende a desechar simbólica y fácticamente la posibilidad de una alteridad

\section{Memorias en combate: invisibilización mediatica y vertederos simbólicos}

A pesar de que para muchos estamos en el boom de la memoria (LeGoff, 1991; Nora, 1998; Halbwachs, 2004; Fontana, 2004), y de que nunca antes en la historia de la humanidad existían tantos trabajos de académicos, intelectuales y grandes monumentos así como solemnes archivos dedicados a la preservación y divulgación de la memoria, también es posible referirnos al campo de los estudios de la memoria como un campo de conocimiento, donde asistimos a la irrupción estruendosa de la lucha contra la memoria y lo que algunos denuncian, como el pesado exceso de memoria (Todorov, 1999; Ricoeur, 2004; Rieff, 2012). Eso hace que podamos afirmar la existencia de una fuerte pugna entre la necesidad de recordar para reconfigurarnos como sociedad o la fuerte pasión del olvido, para darle rienda suelta a la vivencia desaforada del presente.

[...] ya no se trata de una cuestión de decadencia de la memoria colectiva [...], sino de la violación brutal de lo que la memoria puede todavía conservar, de la mentira deliberada por deformación de fuentes y archivos, de la invención de pasados recompuestos y míticos al servicio de los poderes de 
las tinieblas. Contra los militantes del olvido, los traficantes de documentos, los asesinos de la memoria, contra los revisores de enciclopedias y los conspiradores del silencio, contra aquellos que, para retomar la magnífica imagen de Kundera, pueden borrar a un hombre de una fotografía para que nada quede de él con excepción del sombrero, el historiador [...] animado por la austera pasión por los hechos [...] puede velar y montar guardia (Yerushalmi, 1989, p. 25).

La escuela de Frankfurt, en especial Adorno (1998), había precisado con claridad la importancia de la amnesia histórica y del presentismo como un factor fundamental en el desarrollo de las fuerzas progresivas de la mentalidad burguesa y del sistema que lo acompaña: el racionalismo matematizante inherente al proceso de acumulación de capital. El capitalismo necesita, para su correcto funcionamiento un eterno presente, un vida signada por lo inmediato, donde impera el pensamiento rápido y la lógica del disfrute del ahora, esa actualización constante (donde siempre debemos estar a la altura y a las exigencias del momento) se escinde obligatoriamente y de forma abrupta de la posibilidad de un pasado performativo en la experiencia inter-subjetiva.

De forma profética, Adorno logró entender la lógica oculta de la "animosidad contra la historia, el espectro de una humanidad sin recuerdo" (Adorno, 1998, p. 18) cuando atestiguaba como el imparable capitalismo liquidaba la memoria:

Lo que en definitiva no significa sino que el recuerdo, el tiempo y la memoria son liquidados de la sociedad burguesa, según va avanzando esta, como una especie de resto irracional, de modo similar a como la racionalización progresiva industrial reduce, junto con otros restos artesanos, también categorías como la del tiempo de aprendizaje, o lo que es igual, de adquisición de experiencia (Adorno, 1998, p. 18).

La liquidación de la memoria y el arrojamiento del ser a la actualización perenne, como las dos caras de la misma moneda, llevan implícita a su vez una técnica de instrumentalización del pasado: adueñarse de los procesos de creación y elaboración de la memoria. En este sentido, todo el acervo y la huella mnémica, en especial la relacionada con la violencia 
política, se convierte rápidamente en un espacio de batalla simbólica por dominar las técnicas de producción del relato, como Negri y Hardt ya lo habían planteado, el enfrentamiento es exclusivamente por el dominio hegemónico de los mecanismos de producción de la verdad: «La verdad no nos hará libres, pero sí lo hará el tomar el control de la producción de la verdad» (Negri y Hardt, 2000, p. 134). Sin lugar a dudas los resultados de las investigaciones recientes sobre el rol de la memoria (Jelin, 2017) coinciden en que esta juega un papel fundamental en sociedades como la colombiana, que deben asumir innovaciones necesarias para evidenciar procesos transicionales después de largas temporalidades donde el conflicto desdibujó la posibilidad latente de una comunidad imaginada, en particular, los trabajos sobre y para la memoria, deben ser direccionados a la preservación de los imaginarios colectivos que posibiliten la unión, que precisamente, fungen como brújulas en pos de superar el pasado y abrazar críticamente el presente.

Lamentablemente, nada más alejado de la coyuntura polarizante que se padece como una enfermedad ezquizo-paranoica en las actuales decisiones políticas del gobierno Colombiano en cabeza de su actual presidente Ivan Duque. Al momento de finalizar las revisiones de este texto, la lucha por la memoria en Colombia alcanza altas cotas de infortunio que validan la hipótesis de la reescritura del relato en manos de minorías privilegiadas. El Centro Nacional de Memoria Histórica, se encuentra en cabeza de un académico negacionista del conflicto, el Plan de desarrollo del gobierno del presidente Iván Duque quiere dejar en la posteridad histórica un párrafo donde se exalta la labor pacificadora del expresidente y ahora Senador Álvaro Uribe, destacando su aporte mesiánico a la salvación de la nación colombiana. La prestigiosa editorial Santillana enfrenta serias denuncias por un texto de historia para estudiantes de secundaria, donde se destaca la seguridad democrática como elemento clave para normalizar el País.

La implosión del edificio Mónaco, que trata de borrar los símbolos de la tragedia del narco en Medellín, y la creación de una ruta de la memoria que culmine en el museo de la memoria a las víctimas de la violencia narcoterrorista, son esos datos que aparecen como fragmentarios y aislados en la cantidad de noticias sobre realidades externas y fake news en cadenas de whatsaap, pero que obedecen a una lógica de enfrentamiento. 
Sin lugar a dudas, existe un duelo de memorias en las políticas públicas y en la narrativa histórica, que conlleva a la lucha por el poder de contarles a las generaciones futuras lo que ocurrió y lo que se padeció. En palabras de Jelin esta lucha por lo simbólico y el poder de ser el único propietario de las palabras, se debe entender como un conflicto por el lenguaje, donde:

Estas luchas implican, por parte de los diversos actores, estrategias para «oficializar» o «institucionalizar» una (su) narrativa del pasado. Lograr posiciones de autoridad, o lograr que quienes las ocupan acepten y hagan propia la narrativa que se intenta difundir, es parte de estas luchas. También implica una estrategia para "ganar adeptos», ampliar el círculo que acepta y legitima una narrativa, que la incorpora como propia, identificándose con ella, tema al cual volveremos al encarar las cuestiones institucionales en las memorias. (Jelin, 2002, p. 36)

Jelin (2002, p. 60), extrapolando el concepto de Becker de empresarios morales, usa la categoría de análisis de "empresarios de la memoria", los cuales representan grupos sociales con relativo poder para realizar demandas en torno a las marcas de la memoria, los cuales solicitan borrar datos o hechos históricos, reescribirlos o simple y llanamente rescatarlos del olvido. Estos grupos en ocasiones altamente radicalizados en el dominio y apropiación de una memoria, dejan de escuchar al otro, de preocuparse por su alteridad y en ocasiones terminan capturando la narrativa de una memoria como forma de reivindicación política y privativamente, adecuando los relatos de los otros a sus particularidades y exigencias. Chomsky lo plantea de una forma atinada cuando explica como los dominadores hegemónicos controlan los sistemas de construcción de creencias y de reescritura de la historia: "una técnica estándar de formación de creencias es hacer algo para el interés propio y luego construir un marco del cual se deriva que eso es lo correcto" (Chomsky, 2001, p. 2).

En este sentido es factible explicar la actual coyuntura altamente polarizada de la realidad política colombiana. El día 13 de marzo del 2019 en el Senado de la República Colombiana, en una de las sesiones de la comisión de paz, donde precisamente se abordaba el espinoso tema de las objeciones del ejecutivo a la Justicia especial para la paz, ocurrió un hecho, que se suma a estos aconteceres noticiosos, que como ya mencionamos, tienden 
a verse fragmentarios y dispersos en la ya tradicional radicalizada política nacional. Dos grupos de senadores terminaron a los gritos, los del Centro Democratico esgrimiendo su arsenal simbólico, tildaron a los del partido político de las Farc de Narcoterroristas y estos respondieron al apelativo acusando a los del centro democratico de Paracos. Al finalizar la jornada, era claro que, el eco semiótico permeaba las redes sociales y ocupaba gran espacio en los medios noticiosos. Pero ninguno de los análisis revisados señalaba lo oculto a esta gran controversia, una fuerte efervescencia social que toma ímpetu y se radicaliza: la basurización simbólica del otro.

El análisis de basurización simbólica para contextos políticos en conflicto, lo inicia de una forma innovadora Rocio Silva Santisteban (2008), quien basándose en los estudios de los "vertederos simbólicos" del reconocido profesor canadiense Daniel Castillo (1999) toma el contexto geopolítico en el cual ubica Castillo el análisis de subalternidad que se le otorga en la diplomacia a las relaciones de poder entre un centro que es Estados Unidos de América y una periferia que es América Latina, para extender el trabajo a los procesos de exclusión y construcción-de-construcción de la alteridad en sociedades gravemente escindidas y laceradas por la violencia. La mencionada autora, entiende estos procesos de basurización como los mecanismos usados para fragmentar y preservar la exclusión en un proceso donde los mass media juegan un rol vital en la construcción de estigmas: el telepobre, el desplazado, el marginal, el migrante, la víctima, el pobre, el guerrillo. Estas imágenes del otro, posibilitan que el portador de un estigma se convierta en un excremento que debe ser evacuado, botado y al mismo tiempo generan cohesión sobre lo que hay que limpiar, de ahí la idea de un vertedero, donde podamos arrojar a los históricamente excluidos. En este sentido, precisa Silva que: "La basurización simbólica es, pues, la forma como mantenemos al otro como una alteridad radical que no escuchamos, un espacio de descargo y descarga, cuerpo que debe ser evacuado del sistema de forma anónima para que todo siga funcionando". (Silva Santisteban, 2008, p. 93).

Susan Sontag (2003) advertía sobre lo problemático de las practicas que implicaban una expulsión del otro, una deshumanización progresiva frente al dolor de los demás. Seres que no desarrollan empatía, que asumen el dolor del otro como una normalidad (si lo mataron era por que algo debía) y medios masivos de comunicación que proyectan constantemenete 
imágenes desfiguradas de los victimarios: narconovelas que exaltan la figura del sicario, telenovelas donde las prepagos, las viudas de la mafia o los hermanos paramilitares son heroizados y se exalta su modo de vida y de forma amoral, ayudan a preservar y exacerbar estos roles y a consolidar los procesos de basurización y exclusión radical del otro. La ensayista Sontag, lograba explicar que la forma como proyectamos las representaciones del desastre y el dolor que queda después de una guerra, fomentaban la indiferencia o propiciaba el espectáculo, una espectacularización morbosa que alimenta las fuerzas destructoras de la repetición. Denigrar la realidad producto de la violencia política es construir procesos silenciosos de insensibilidad social.

La construcción iconográfica de las imágenes del dolor en todas las dimensiones se constituyen en esta mirada critica, en elementos catalizadores o en elementos normalizadores. Sontag lo afirmaba con las implicaciones semióticas del poder "normalizador" de las imágenes: "Nosotros -y este "nosotros" es todo aquel que nunca ha vivido nada semejante a lo padecido por ellos- no entendemos. No podemos imaginar lo espantosa, lo aterradora que es la guerra; y cómo se convierte en normalidad. No podemos entenderlo, no podemos imaginarlo" (Sontag, 2003, p. 146). Los procesos de vertimiento simbólico ocurren en Colombia desde los inicios de la colonización a sangre y fuego por los conquistadores Españoles. Estos procesos aun permean los imaginarios: indio, negro, mestizo. Posteriormente con el auge de la república liberal en el siglo XIX, estos apelativos se fueron direccionando a los pobres históricos, con el famoso miedo al pueblo. Este miedo era portador de los imaginarios históricos y depositaba en "los de ruana" los estigmas fundacionales y convertía a los pobres históricos en los aplazados, en los ciudadanos postergados y por ende el Estado se constituía en una ficción inalcanzable para este tipo de poblaciones. Los procesos virales que producen indignación, tal y como lo afirmo el jefe de la campaña por el No en el proceso fallido de plebiscito para refrendar los acuerdos de paz, en una entrevista al diario la República: "Nuestra campaña fue hecha con base en la indignación. Queríamos que la gente saliera verraca a votar". Trabajos posteriores demostraron que una gran parte de la población colombiana no entendía por qué votaba, pensaban en su mayoría que decir No, era evitar la ideología de género en 
el sistema educativo y el pago de un sueldo millonario a los guerrilleros que abandonaran las armas (Revista Semana, 2019, p. 30).

La producción de basura simbólica se direcciona a la creación de e-paranoias, que con storytelling altamente virales que se propagan en las redes sociales y colonizan la opinión pública, exacerban nuestros odios e impiden entender y escuchar al otro. En este panorama de viralizacion del odio, es practicamente imposible construir un espacio donde las partes se escuchen, donde las memorias tradicionalmente silenciadas a balazos, puede ser escuchadas, donde el coro polifónico pueda evidenciar las tragedias del dolor y cuando menciono tragedias, es la de todos sin excepción. Solo cuando tengamos una sociedad que pueda, quiera y aprenda a escuchar, podremos asumir la transición para un postconflicto exitoso. De lo contrario seguiremos atrapados en el hechizo del pasado, con las estructuras intactas para la repetición, en un círculo sin fin, como la trágica metáfora Hindú de la serpiente que se devora a si misma.

En solo tres meses de lo corrido del año 2019, han ocurrido 7 masacres con el saldo trágico de 30 muertos (Revista Semana, 2019), que como en las peores épocas del conflicto exacerbado entre Estado y Guerrilla, nos traen los asesinatos por degollamiento, las típicas torturas barbáricas a cuerpos en múltiples ocasiones lacerados hasta el cansancio, los tiroteos indiscriminados y la posibilidad inminente de la repetición a manos de nuevos actores que de forma violenta, a bala y sangre, luchan por copar los espacios dejados por la guerrilla de las Farc (Narcos, disidencias de las Farc, grupos posparamilitares, contrabandistas y delincuencia común, o lo mas grave sus constantes hibridaciones). En la memoria, a diferencia de la repetición traumática, el pasado no invade el presente sino que lo informa. (Jelin, 2002, p. 69) Según el Grupo de Memoria Histórica (2013), desde el año 1985 y hasta la firma de los acuerdos, en el país murieron 12 mil personas por cuenta de las masacres, sus blanco predilecto eran la población rural, la que habita en la tierra del olvido y su estrategia era pedagógica, enseñar a través de las marcas destructivas de los cuerpos humanos, lo que podía ocurrir en caso de no aceptar las órdenes del patrón de patrones en turno.

En la actualidad, las masacres se han incrementado de manera exponencial y la muerte de los líderes sociales demuestra una sistematicidad: entre el primero de enero del 2016 y el 21 de diciembre del 2018, según 
el Centro Nacional de Memoria Histórica (2018) fueron asesinados 431 líderes sociales, en su mayoría líderes de grupos empoderados en pos de la defensa de las víctimas y de los reclamantes de tierras o personas defensoras de los Derechos Humanos. Esta ferocidad no se detiene, en solo dos semanas del año 2019, ya habían muerto 7 líderes sociales, sin que la fiscalía logre visibilizar y desarticular las estructuras oscuras que organizan estos asesinatos.

Lo más doloroso de estos hechos, que como se ha comentado a lo largo del trabajo se tornan advertencias de lo infausto de transitar el camino de la repetición, es la baja cobertura mediática que reciben. La razón es simple y la precisa Castells (2009), en su trabajo sobre la comunicación y el poder. La centralización de los medios en grandes grupos trasnacionales, donde, y aquí es necesario subrayarlo, las élites familiares tradicionales glocalizadas detentan el poder, escogen las narrativas y centralizan en el proceso de doble flujo comunicacional (medios, lideres, opinión pública) los frames (marcos cognitivos) y los priming (primacia de la memoria) para orientar precisamente el pensamiento y las agendas políticas. Este proceso de imposición de agenda informativa, no nos dice qué pensar, solo nos induce sobre que pensar.

Lastimosamente, las víctimas, los desplazados, los migrantes, los pobres históricos, la infraclase, no vende, no es un producto que genere rating o niveles altos de sintonía, todo lo contrario es un producto difícil de ajustar a las exigencias del relato telegénico o del marketing mediático. Solo es noticia cuando precisamente rompe los moldes de su exclusión y se torna en tragedia espectacularizada y altamente amarillista. El rol de los medios para orientar sobre la información del pasado en el presente es fundamental, los medios generan basura simbólica y podrían terminar siendo cómplices en la producción de desechos simbólicos.

En este sentido, la agenda mediática en términos de Bourdie (2005), termina mostrando y al hacerlo oculta deliberadamente, es decir señala unos problemas que, a juicio de los detentadores del poder mediático, son fundamentales y deben ser priorizados por la agenda pública. Por lo general no hay coincidencia de agendas y lo que podemos apreciar es una pugnacidad entre las agendas y, quien gane la batalla, logrará el poder que implica definir e implementar una narrativa. El secuestro de la agenda por algunos de los grupos de presión implica que las acciones políticas y, 
en gran medida, la gobernabilidad de la agenda pública, sean orientadas, ya sea por la agenda ciudadana en el marco de grandes movilizaciones y protesta social o por la fuerza de la agenda mediática, que a su vez logra grandes viralizaciones y olas de indignación a través de la colonización de la opinión pública, hoy medida por los famosos trending topic.

En este orden de ideas, en muy raras ocasiones se logra la coincidencia de estas tres agendas. El reconocido analista de la opinión pública Fermín Bouza, denomina a este proceso sui generis de convergencia de agendas como zona de impacto de la comunicación política, el cual lleva por consecuencia ser fomentador de puntos de quiebre: "La coincidencia plena entre agendas se da solo en períodos de alta tensión política y ciudadana, en verdad son casos muy excepcionales los que posibilitan un punto de quiebre" (Bouza, 2007, p. 32)

Si analizamos detenidamente el punto de quiebre, podemos sostener que surge cuando, frente a las manifestaciones sociales, los medios se ven obligados a hacer un cubrimiento masivo de la temática, lo que a su vez obliga a que el gobierno direccione su agenda pública y la construcción de políticas públicas a dar satisfacción a los reclamos ciudadanos. Bouza y Rodríguez (2017) definen la zona de impacto clarificando el rol de los medios que movilizan ciudadanía para lograr cambios reales, en especial cuando se crea una identificación plena entre lo público, es decir, cómo el yo cognitivamente hace lo público suyo:

Aquella área temática es más sensible a la comunicación pública en general y a la comunicación política en particular, porque es el área en la que el individuo siente una clara coincidencia entre el país y él mismo: una agenda mixta que tiene la fuerza de lo general y lo particular, y por ello mismo parece esa agenda por la que el individuo se siente más inclinado a presionar, al tiempo que es más receptivo a toda comunicación que se haga sobre ese bloque temático mixto. (p. 22) 


\section{Conclusión}

Es pertinente señalar que el trabajo ha explorado las problemáticas globales con impacto local, así mismo, ha reflexionado críticamente sobre el combate por imponer narrativas en el marco de las dinámicas posviolentas de una sociedad transicional como la colombiana, enfatizó en la debilidad de los frames ante la simplificación excesiva de la realidad y ha recalcado la fuerte tendencia para liquidar la memoria en el mundo de la manipulación mediática y la imposición elitizada de narrativas pseudohistoricas. Se considera que, en este punto de la coyuntura política Colombiana, estamos como Harum, el aventurero genial (Rushdie, 2011), que una mañana se levantó sin el poder de sus historias, había olvidado sus superlativas e inspiradoras historias y le tocó iniciar una búsqueda en el mar de las historias perdidas, surcar este océano repleto de trampas arriesgadas y enemigos poderosos, le permitió poder encontrar su narrativa, poder desentrañar su pasado. Quisiéramos poder sentir la tranquilidad de Harum al encontrar su memoria surcando con entereza las olas fragorosas de la evocación, pero para nosotros, para Colombia y su tierra del olvido, la travesía apenas empieza.

\section{Referencias}

Acemoglu, Daron; Robinson, James (2012). Por que fracasan los países. Barcelona: Deusto.

Adorno, Theodor (1998). Educación para la emancipación. Conferencias y conversaciones con Helmut Becker (1959-1969). Madrid: Ediciones Morata.

Bauman, Zygmunt (2009). Tiempos líquidos. Barcelona: Tusquets.

Bourdieu, Pierre (2005). Sobre la televisión. Barcelona: Anagrama.

Bouza Alvarez, Fermín; Rodriguez Díaz, Raquel (2017). Área de impacto de la comunicación política: estudio de caso. Sociologiados revista de investigación social. Vol. 2, noviembre de 2017. pp. 19-34.

Bouza, Fermín (2007). The impact area of political communication: citizenship faced with public discourse, International Review of sociology. Revue internationale de sociologie, Vol. 14 n 2. pp 245-259. 
Burguiere, André (1976). Introduction. En: Foster, R.; Ranum, O. Family and society: selection from the annales economies, societies, civilization. Baltimore: Jhohn Hopkins University Press.

Bushnell, David (2007). Colombia una nación a pesar de sí misma. Bogota: Planeta.

Caballero, Antonio (2018). Historia de Colombia y sus oligarquías. Bogotá: critica.

Castells, Manuel (2009). Comunicación y poder. Barcelona: alianza.

Castillo, Daniel (1999). «Culturas excrementicias y postcolonialismo», en DE TORO, Alfonso y Fernando DE TORO (eds.). El debate de la postcolonialidad en Latinoamérica. Una postmodernidad periférica o cambio de paradigma en el pensamiento latinoamericano. Leipzig/ Winnipeg, Vervuert-Iberoamericana. Pp. 235-57.

Castillo, Daniel (2002) «Los oscuros senderos de los vertederos latinoamericanos. Por una estética de la basura en la literatura de Arguedas, Paz y Sábato», en CASTILLO, Daniel y Borka SATLLER (eds.). Perú en su cultura. Ottawa: Universidad de Ottawa - Prom Perú. Pp. 13-53.

Centro Nacional de Memoria Historica (2018). Masacres. En: http://www. centrodememoriahistorica.gov.co/noticias/noticias-cmh/el-bloque-calima-cometio-119-masacres-entre-1999-y-2004

Chomsky, Noam (2001). «Superando las ortodoxias». Entrevista de David Barsamian. Rebelión, 8 de febrero de 2001. Visitada el 15 de marzo de 2001. http://www.rebelion.org/chomsky/ortodoxias080201.htm

Departamento Administrativo Nacional de Estadísticas (2016). Las cifras reales del campo Colombiano. En: https://www.incp.org.co/dane-presenta-las-cifras-reales-del-campo-colombiano/

De la Calle, Humberto (2019). Revelaciones al final de una guerra. Bogotá: Debate.

Fondo Internacional Para el Desarrollo Agrícola (2015). Invertir en la población rural de Colombia. En: https://www.ifad.org/documents/38714170/39150184/Investing+in+rural+people+in+Colombia++S.pdf/d03blc54-eb02-4375-a637-786733e3c8f3 
Fontana, Josep (2004). ¿Para qué sirve la historia en un tiempo de crisis? Bogotá: Ediciones Pensamiento Crítico/Colección Mundo sin fronteras.

Foreing Policy (2018). Index Fragille States. En: https://fundforpeace.org/ fsi/wp-content/uploads/2018/04/951181805-Fragile-States-Index-Annual-Report-2018.pdf

Grupo de Memoria Historica (2013). ¡BASTA YA! Colombia: Memorias de guerra y dignidad. Bogotá: Imprenta Nacional.

González González, Fernán (2014). Poder y violencia en Colombia. Bogota: Cinep.

Halbwachs, Maurice (2004). La memoria colectiva. Zaragoza: Prensas Universitarias de Zaragoza.

Jelin, Elizabeth (2002). Los trabajos de la memoria. Buenos Aires: Siglo XXI.

Jelin, Elizabeth (2017). La lucha por el pasado: como construimos la memoria social. Buenos Aires: Siglo XXI.

Latorre-Iglesias, Edimer (2009). De aplazados a desplazados: la realidad de los derechos de las personas en condición de desplazamiento forzoso en la ciudad de Santa Marta. Bogotá: Fondo de publicaciones Universidad Sergio Arboleda.

Latorre-Iglesias, Edimer (2012). Comunicación, memoria y resiliencia. Bogotá: Fondo de publicaciones Universidad Sergio Arboleda.

Latorre-Iglesias, Edimer (2015). Litigio estructural y experimentalismo jurídico : análisis sociojurídico a los cambios generados por la sentencia T-025 en la población desplazada. Bogotá: fondo de publicaciones Universidad Sergio Arboleda.

Latorre-Iglesias, Edimer (2017). Participación ciudadana y democracia experimentalista en la constitución política de 1991: análisis de una realidad local en Colombia. Bogotá: fondo de publicaciones Universidad Sergio Arboleda.

Leal Buitrago, Francisco (2007). Siete tesis sobre el relevo de las elites políticas. En revista Colombia Internacional (66). Pp. 196-197.

LeGoff, Jacques (1991). El orden de la memoria: el tiempo como imaginario. Barcelona: Paidós. 
Liévano Aguirre, Indalecio (2015). Los grandes conflictos sociales y económicos de nuestra historia. Bogotá: Intermedio.

López Michelsen, Alfonso (1953). Los elegidos. Bogotá: Oveja negra.

Martin de la Fuente, David (2018). Radiografía del poder en Colombia: elites y vínculos de parentesco. Cambios y continuidades desde la teoría de las redes. Tesis de grado para optar al titulo de Magister en Estudios Latinoamericanos. Universidad de Salamanca.

Mejía Quintana, Oscar (2007). Elites, eticidades y Constitución. Cultura política y poder constituyente en Colombia. En publicación: Filosofía y teorías políticas entre la crítica y la utopía. Hoyos Vásquez, Guillermo. CLACSO, Consejo Latinoamericano de Ciencias Sociales, Buenos Aires. 2007. ISBN: 978-987-1183-75-3.

Michells, Robert (2008). Los partidos políticos: un estudio sociológico de las tendencias oligárquicas de la democracia moderna. Buenos Aires: amorrortu.

Negri, Tony; Hardt, Michael (2000). Imperio. Traducción Eduardo Sadier de la Edición de Harvard University Press, Cambridge. Revisado el 25 de junio de 2002. http://www.chilevive.cl/libros/Imperio-Negri-Hardt.pd

Nora, Pierre (1998). "La aventura de Les lieux de Mémoire". Ayer. Revista de la Asociación de Historia Contemporánea 32 (1998): 17-34.

Oquist, Paul (1978). Violencia, conflicto y política en Colombia. Bogotá: Biblioteca Banco Popular

Pardo, José Luis (2016). Estudios del malestar: políticas de la autenticidad en las sociedades contemporáneas. Barcelona: Anagrama.

Revista Semana (2019). Un país dividido. Edición numero 1924. 17 al 24 de marzo de 2019. Pp. 30, 40-41.

Reveiz, Edgard (2007). El Estado regulador de riesgos. Bogotá: Academia Colombiana de ciencias económicas.

Reveiz, Edgard (2016). La transgresión moral de las elites y el sometimiento de los Estados: cooptación o democracia. Bogotá: Academia Colombiana de ciencias económicas.

Reyes Morris, Víctor (2016). La anomia: espacios, tiempos y conflictos anómicos. Analisis de casos. Bogotá: ediciones aurora. 
Ricoeur, Paul (2004). La historia, la memoria, el olvido. Buenos Aires: Fondo de Cultura Económica

Rieff, David (2012). Contra la memoria. Barcelona: Debate.

Ritzer, George (2007). La globalización de la nada. Barcelona: editorial popular.

Robinson, James (2014). La realidad colombiana. En: Ronderos, María Teresa (2014). Guerras recicladas: una historia periodística del paramilitarismo en Colombia. Bogotá: Aguilar.

Rulfo, J. (1983). Pedro páramo. El llano en llamas. Bogotá: Círculo de lectores.

Rushdie, Salman (2011). Harum y el mar de las historias. Barcelona: Random House

Serrano, Enrique (2016). ¿Por qué fracasa Colombia? Bogotá: Planeta.

Silva Colmenares, J. (1977). Los verdaderos dueños del país: oligarquía y monopolios en Colombia. Bogotá: Sudamericana.

Silva Santisteban, Roció (2008). El factor asco: basurización simbólica y discursos autoritarios en el Perú contemporáneo. Lima: red para el desarrollo de las ciencias sociales en el Perú.

Sontag, Susan (2003). Ante el dolor de los demás. Bogotá: Alfaguara.

Todorov, Tzvetan (1999). Los abusos de la memoria. Barcelona: Ediciones Paidós.

Waldman, Peter (2007). Guerra civil, terrorismo y anomia social. El caso Colombiano en un contexto globalizado. Bogotá: Grupo editorial norma.

Yerushalmi, Yosef H. (1989). Reflexiones sobre el olvido. En: A.A.W. Usos del olvido. Buenos Aires: Nueva Visión.

Zizek, Slavoj (2018). El coraje de la desesperanza: cronica del año en que actua,os peligrosamente. Barcelona: Anagrama. 